\title{
Endothelin-1 impairs neutrophil respiratory burst and elimination of Escherichia coli in rabbits
}

Axel Heller, MD; Joachim Schmeck, MD; Susanne Heller, MD; Hoa Phan, Cand.Med.; Thomas Nebe, MD; Renate Urbaschek, MD; Thea Koch, MD, PhD

From the Departments of Anesthesiology and intensive Care Medicine, University Hospital Carl Gustav Carus, Dresden (Drs. A. Heller, S. Heller and Koch), University Hospital, Mannheim (Drs. Schmeck and Phan), Institute of Clinical Chemistry, University Hospital, Mannheim (Dr. Nebe), and the Institute of Medical Microbiology and Hygiene, University Hospital, Mannheim (Dr. Urbaschek), Germany.

Supported, in part, by the Deutsche Forschungs-gemeinschaft (DFG, K01814/2-1) and the Research Fund of the Faculty of Clinical Medicine Mannheim, University of Heidelberg, Heidelberg, Germany.

Address requests for reprints to: Axel Heller, MD, Klinik für Anaesthesiologie und Intensivtherapie, Universitätsklinikum Carl Gustav Carus, Fetscherstrasse 74, D-01309 Dresden, Germany E-mail: hellera@rcs.urz.tu-dresden.de

Objective: During systemic inflammation, elevated levels of endothelin (ET)-1 have been reported. The aim of this study was to investigate the effects of ET-1 on neutrophil (PMN) respiratory burst, phagocytosis, and elimination of Escherichia coli from blood and tissues.

Design: Prospective, randomized, controlled trial.

Setting: Experimental laboratory in a university hospital.

Subjects: A total of 18 female chinchilla rabbits.

Interventions: To quantify the clearance process, defined numbers $\left(10^{8}\right.$ colonyforming units) of $E$. coli were injected intravenously into anesthetized rabbits, 60 mins after onset of continuous $0.2 \mu$ $\mathrm{g} / \mathrm{kg} / \mathrm{min}$ ET-1 administration $(\mathrm{n}=9)$ and after saline infusion (control group, $n=9$ ), respectively. To evaluate potential effects of ET-1 on bacterial elimination and killing, blood clearance of $E$. coli and colonization of different organs were investigated.
Measurements: Variables monitored were neutrophil respiratory burst and phagocytosis activity, rates of bacterial elimination from the blood, arterial blood pressure, blood gases, serum lactate concentrations, and nitrite and nitrate levels. The animals were killed 3 hrs after bacterial injection and tissue samples of liver, kidney, spleen, and lung were collected for bacterial counts.

Main results: Compared with the control group, ET-1 significantly impaired PMN respiratory burst $(p<.05)$ and prolonged elimination of injected $E$. coli from the blood $(p<.01)$, whereas phagocytosis functions remained unaltered. The reduced PMN burst activity after ET-1 was associated with a higher bacterial colonization of all organs (lung, $p<.01$; spleen, $p<.05)$. Endothelin-1 induced increases in mean arterial pressure ( $p$ $<.01)$ and serum lactate concentrations, whereas nitrite and nitrate levels remained unaltered. 
Conclusion: Endothelin-1 impairs respiratory burst and bacterial clearance from the blood and tissue. Thus, elevated levels of ET-1 during sepsis could induce organ hypoperfusion and cause disturbances in immune functions, increasing the risk of bacterial infections.

In spite of intensive research efforts and improved therapeutic strategies, the prevalence and mortality rate of sepsis in trauma patients remains high, thus pointing toward a reduced resistance against invasion of bacteria and their toxins into the circulation and colonization of different organs. In previous experiments, impairment of defense mechanisms, particularly of the bacterial clearance from the blood, were described after experimental activation of the coagulation system and the complement cascade (1), or after induction of hypoxia or hemorrhagic shock (2). Endothelin (ET)-1, a peptide with vasoconstrictive properties, was first described in 1988 by Yanagisawa et al. (3). In the last decade, various actions were found to be induced by ET-1, such as bronchoconstriction $(4,5)$, stimulation of leukocytes (6), and mitogenesis (7). Because elevated plasma concentrations have been detected during sepsis $(8,9)$, the role of ET1 as a mediator of septic complications is currently under investigation. Endothelin-1 levels were elevated after endotoxin application (10) indicating the impact of ET1 in inflammatory diseases. Furthermore, ET-1 plays an important role as a mediator of granulocyte-mediated lung injury (11). However, it is not known whether ET-1 only affects vascular reactions $(12,13)$ or whether ET-1 also promotes the development of inflammatory diseases by influencing host defense mechanisms such as neutrophil (PMN) respiratory burst and phagocytosis activity or monocyte functions (14). To clarify the pathogenic role of ET-1 in inflammatory diseases, the aim of this
KEY WORDS: respiratory burst; phagocytosis; neutrophils; bacterial clearance; bacterial killing; endothelin-1; sepsis; systemic inflammatory response syndrome; lung injury; Escherichia coli; endotoxin

study was to examine the effects of ET-1 on PMN immune functions, bacterial killing capacity, and systemic blood pressure in anesthetized rabbits. To simulate bacterial invasion from various compartments, such as the gut, the urogenital tract, wounds, or implanted catheters into the circulating blood and to enable quantification of the clearing process, a defined number of exogenous Escherichia coli $\left(10^{8}\right.$ colonyforming units [CFU]) was injected intravenously 60 mins after starting the infusion of ET-1 $(0.2 \mu \mathrm{g} / \mathrm{kg}$ of body weight $/ \mathrm{min}$ ) or sodium chloride (control group). Respiratory burst activity and phagocytosis of granulocytes, as well as the elimination kinetics of exogenous $E$. coli and endotoxin (LPS) from the blood and the bacterial tissue distribution in the liver, spleen, kidney, and lung were studied.

\section{MATERIALS AND METHODS}

Animal Model. A total of 18 female chinchilla rabbits weighing between 2 and 3 $\mathrm{kg}$ were anesthetized with ketamine (Ketanest; Parke Davis, Berlin, Germany, 50 $\mathrm{mg} / \mathrm{kg}$ body weight.) and xylazine (Rompun; Bayer, LeverKusen, Germany, $4 \mathrm{mg} / \mathrm{kg}$ body weight) and anticoagulated with heparin-sodium (1000 IU/kg body weight) injected into an ear vein catheter. The animals were placed in a supine position on a temperature-controlled $\left(35^{\circ} \mathrm{C}\left[95^{\circ} \mathrm{F}\right]\right)$ operating table. After tracheostomy and intubation, the rabbits were mechanically ventilated with room air (tidal volume, 30 $\mathrm{mL}$; frequency, 30 cycles $/ \mathrm{min}$ ) via 
respiratory support (Servo 900D; Siemens Elema, Solna, Sweden) during the whole observation period. A polyvinyl chloride catheter $(1.4 \mathrm{~mm})$ was inserted into the right carotid artery for measurements of arterial blood pressure and for collection of blood samples. While monitoring the hemodynamic condition, anesthesia was maintained by injection of $5-10 \mathrm{mg} / \mathrm{kg} / \mathrm{hr}$ ketamine and $0.5-1.5 \mathrm{mg} / \mathrm{kg} / \mathrm{hr}$ xylazine. In addition to the basal fluid requirement of 3-4 $\mathrm{mL} / \mathrm{kg}$ body weight, blood loss from sampling was replaced by isovolemic injection of saline.

Monitoring. After instrumentation of the rabbits, arterial and airway pressures were continuously monitored via Statham strain gauge transducers connected to a recorder (Sirecust 404A; Siemens). Blood samples were drawn intermittently for measurements of $\mathrm{pH}, \mathrm{PaO}_{2}, \mathrm{PaCO}_{2}, \mathrm{HCO}_{3}$, hemoglobin, oxygen-saturation, and hematocrit (288 Blood Gas System, Ciba Corning, Fernwald, Germany), as well as of leukocyte and differential blood counts. The PMN burst and phagocytosis activity, serum lactate (test-combination lactate, fully enzymatic; Boehringer, Mannheim, Fernwald, Germany) and nitrite and nitrate $\left(\mathrm{NO}_{\mathrm{x}}\right)$ concentrations were determined according to the protocol.

Bacterial Inoculum. An encapsulated, serum-resistant, nonhemolytic strain of $E$. coli (0111) with a smooth LPS phenotype, freshly isolated from blood of a septicemic patient, was cultured on blood agar plates. After $10 \mathrm{hrs}$ of incubation at $37^{\circ} \mathrm{C}\left(98.6^{\circ}\right.$ $\mathrm{F})$, the colonies were harvested and homogenized by vortexing in tryptic soy broth, adjusted to a density of $10^{8} \mathrm{CFU} / \mathrm{mL}$ and frozen in aliquots at $-70^{\circ} \mathrm{C}\left(-94^{\circ} \mathrm{F}\right)$ until use. The used amount of $10^{8} \mathrm{CFU} E$. coli in the current study was based on pilot experiments providing a reproducible clearance rate and organ distribution without inducing severe hemodynamic changes that might influence clearance function by tissue hypoperfusion. In control group animals, the injection of $10^{8} \mathrm{CFU}$ E. coli was completely cleared from the circulation during the time period of 60 to 90 mins, thus allowing registration of acceleration or impairment of the clearance kinetics in the different experimental groups.

Experimental Protocol. After a 30min period of stable hemodynamics, the animals were randomly assigned to one of two respective groups. Then, the first blood samples for baseline measurements were collected.

Control Group $(n=9)$. After a 60 min period during which saline was infused $(0.1 \mathrm{~mL} / \mathrm{min})$, the standardized amount of $E$. coli $\left(10^{8} \mathrm{CFU}\right.$ suspended in $1 \mathrm{~mL}$ of tryptic soy broth) was injected into the ear vein catheter. For bacterial analysis, arterial blood was aseptically drawn at $1,5,15,30$, 45, 60, 90, 120, 150, and 180 mins after bacterial injection. Blood gases, leukocyte counts, hematocrit, and hemoglobin concentrations were determined at 30-min intervals. Neutrophil oxidative burst and phagocytosis activity were determined before, and at 5, 30, 90, and $180 \mathrm{~min}$ after $E$. coli injection. At the end of the experiment the animals were killed with ketamine and xylazine. Subsequently, tissue samples of liver, spleen, kidney, and lung were removed under aseptic conditions for bacterial cultures.

ET-1 group $(n=9)$. At 60 mins after onset of ET-1 infusion $(0.2 \mu \mathrm{g} / \mathrm{kg} / \mathrm{min})$ (Alexis, Läufelfingen, Switzerland), which was continued until the end of the observation period, $10^{8} \mathrm{CFU}$ E. coli were injected and the same protocol as in the control group was followed. Endothelin-1 was dissolved in dimethylsulfoxide (Merck, Darmstadt, Germany) and adjusted to the final concentration with isotonic saline $(\mathrm{pH}$ 6.95). 
The used dose of ET-1 was tested in dose-response studies in which the concentration of $0.2 \mu \mathrm{\mu} \quad \mathrm{g} / \mathrm{kg}$ body weight/min was able to induce a reproducible increase in arterial blood pressure, whereas higher concentrations of ET-1 killed the animals within 30 mins.

Neutrophil Burst Activity. The amount of intracellular oxygen radical production was determined in freshly drawn heparinized whole blood. A test kit (Bursttest; Orpegen Pharma, Heidelberg, Germany) for the determination of the oxidative burst of leukocytes in whole blood was used. Single cell analysis was performed by flow cytometry. The method of the quantitative assay for monitoring the oxidative burst was previously described in detail (15). Two assays (100 $\mu \mathrm{L})$ of each sample were incubated $\left(10 \mathrm{mins}\right.$ at $37^{\circ} \mathrm{C}$ $\left.\left[98.6^{\circ} \mathrm{F}\right]\right)$ with either phosphate-buffered saline (negative control), or with E. coli opsonized with antibodies and complement from pooled sera. Escherichia coli stimulates production of reactive oxygen intermediates. After the oxidation step (incubation with substrate $10 \mathrm{mins}$ at $37^{\circ} \mathrm{C}$ $\left[98.6^{\circ} \mathrm{F}\right]$ ) in which the nonfluorescent substrate, dihydrorhodamine 123 , was taken up by the phagocytes and converted during the respiratory burst to a green fluorescent compound (rhodamine 123), the whole blood was lysed and fixed. This oxidation is highly specific for the respiratory burst activity. To guarantee that no cell debris, dead cells, or bacteria would interfere with the measurement, DNA staining was performed with propidiumiodide (red fluorescence, FL-3). A quantity of 15,000 cells of each sample was measured with a laser flow cytometer (FACS-can/Lysis II; Becton Dickinson, Heidelberg Germany) by using a blue-green excitation light (488-nm argon laser). The photomultiplier gain setting was adjusted to register all intensities of cellular fluorescence within the scale of 256 channel resolution (4 decades). Neutrophils were identified by their characteristic size to granularity ratio. Only the selected cell population was considered for further analysis by using a multiple document interface for Windows 3.1 (WinMDI 2.0; by J. Trotter, Scripps Research Institute, LaJolla, CA). During data acquisition, a "live" gate was set in the red fluorescence dot plot on those events that had at least the same DNA content as rabbit diploid cells. Only these cells were examined. For characterization of the fluorescence distribution, the mean channel fluorescence per cell was used, indicating the amount of rhodamine 123 per cell.

Neutrophil Phagocytosis Activity. A test kit (Phagotest; Orpegen Pharma) for the determination of the phagocytic activity of leukocytes in whole blood was used. Single cell analysis was performed by flow cytometry. The method of the quantitative assay for investigating the phagocytic activity has been previously described in detail (16). Two assays of each sample $(2 \times$ $100 \mu \mathrm{L}$ ) were incubated with fluorescence isothiocyanate-marked opsonized $E$. coli either at $0^{\circ} \mathrm{C}\left(32^{\circ} \mathrm{F}\right)$ (control group) or at $37^{\circ} \mathrm{C}\left(98.6^{\circ} \mathrm{F}\right)$ for $10 \mathrm{mins}$. Cells of the phagocytic system have receptors for a complement fragment $3 \mathrm{~b}$ and for the constant part of the immunoglobulin molecule crystallizable fragment mediating the adhesion of the bacteria to the cell surface and subsequent engulfment. During the incubation period the fluorescence isothiocyanate-marked $E$. coli were ingested in the $37^{\circ} \mathrm{C}\left(98.6^{\circ} \mathrm{F}\right)$ assay. To exclude extracellular bacteria from measurement, they were quenched with a staining solution. The further steps, such as lysis, fixation, DNA-staining, and data acquisition by flow cytometer were performed in the same manner as in the burst-assay. The phagocytosis activity of leukocytes was 
determined by the content of fluorescence isothiocyanate-marked $E$. coli in the phagocytic cells, expressed as mean channel fluorescence per cell.

\section{Quantitative Microbiology}

Blood and tissue samples were chilled and assayed in duplicate after the end of the experiment. After incubation of the cultures at $37^{\circ} \mathrm{C}\left(98.6^{\circ} \mathrm{F}\right)$ for $24 \mathrm{hrs}$, the CFUs of E. coli were counted. The final bacterial concentration was calculated as the number of colonies per $\mathrm{mL}$ of blood, or as colonies per $g$ of tissue, respectively.

Blood Cultures. Blood samples were serially diluted in sterile saline. According to Sandys' technique (17), $100 \mu \mathrm{L}$ of whole blood and of each dilution step were plated onto cysteine lactose electrolyte-deficient agar plates.

Organ Cultures. Aseptically collected organs, liver, spleen, lung, and kidney were weighed, and $0.8-2 \mathrm{~g}$ of each organ were homogenized (Ultra-Turrax, IKA-Werke, Staufen, Germany) in $3 \mathrm{~mL}$ of sterile saline. Serial dilutions of tissue suspension (100 $\mu \mathrm{L})$ were plated onto cysteine lactose electrolyte deficient agar plates.

Detection of Endotoxin. To take into account plasma-related factors that interfere with limulus amebocyte lysate endotoxin reaction and considering the fact that each plasma sample has a different slope of the standard curve when spiked with endotoxin, an automated, kinetic, turbidimetric limulus amebocyte lysate microtiter test with individual internal standardization was used $(18,19)$. The principle is to establish an endotoxin reference curve in each sample by spiking the samples (diluted 1:5 and heated 10 mins at $80^{\circ} \mathrm{C}\left[176^{\circ} \mathrm{F}\right]$ ) with different LPS (NP3 Novo Pyrexal; Weidner, Waldorf, Germany) concentrations. After addition of lysate (Pyrotell; Associates of Cape Cod, Weidner, Waldorf, Germany) the increase in optical density was measured at $37^{\circ} \mathrm{C}$ $\left(98.6^{\circ} \mathrm{F}\right)$ at $30-\mathrm{sec}$ intervals for $100 \mathrm{mins}$ at $405 \mathrm{~nm}$ (Thermomax Photometer, Heidelberg, Germany). The deviation from the linear slope in the lower range of the spiked LPS represents the endogenous unknown endotoxin content of the sample. The sensitivity of this assay is $0.1 \mathrm{pg} / \mathrm{mL}$.

\section{Measurement of Nitrite and Nitrate}

A commercially available colorimetric test kit was used for the determination of total $\mathrm{NO}_{\mathrm{x}}$ concentration in a two-step process (Cayman Chemicals, Ann Arbor, MI). In the first step, nitrate was converted into nitrite utilizing nitrate reductase. After that step, Griess reagent (20) that converts nitrite into a deep purple azo compound was added. Photometric measurement (AR 2001 photometer, Anthos Lab. Instruments, Krefeld, Germany) of the light absorption at $540 \mathrm{~nm}$ caused by this azo chromophore determines the $\mathrm{NO}_{2}$ concentration. Azide, ascorbic acid, dithiothreitol, and mercaptoethanol interfere with the color development in concentrations of $100 \quad \mu \quad M \quad$ and phosphate $>50 \mathrm{mmol}$ interferes with the conversion of nitrite to nitrate.

\section{Histology}

Representative tissue samples of liver, lung, spleen, and kidney were frozen in liquid nitrogen. Then, they were cut into slices of $10 \mu \mathrm{m}$ for light microscopic examination.

Statistical Analysis. Data are presented as the arithmetic mean \pm SEM. The logarithm of bacterial counts was used for statistical comparison. Differences between the two groups were tested by Student's $t$-test. Significance was accepted at $p<.05$.

Experiments were performed in agreement with the commission for animal protection of the local government. The care and handling of animals were in accordance 
with the National Institutes of Health guidelines.

\section{RESULTS}

Respiratory Burst Activity of Neutrophil. Baseline values of respiratory burst activity, expressed as mean fluorescence intensity per cell (Fig. 1) and obtained before infusion of ET-1 (57 \pm 5$)$, did not show any significant difference compared with the control group (49 \pm 12$)$. The intensity of the burst reaction in the control group remained widely unaltered during the observation period, whereas ET-1 induced a depression of the respiratory burst significant at 5, 90, and 180 mins $(p<.05)$ after injection of E. coli.

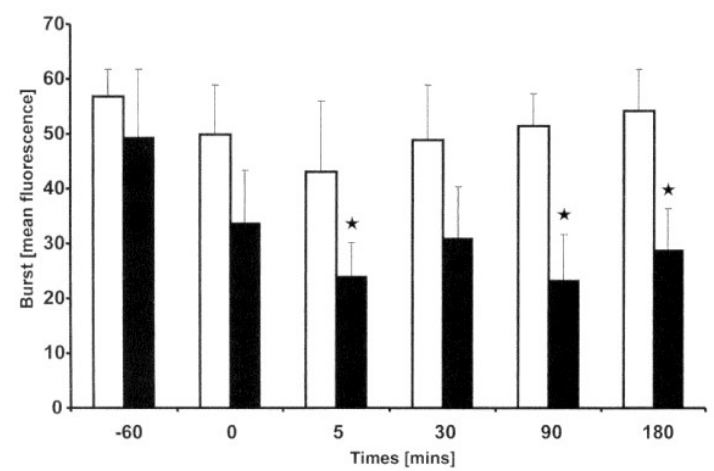

Figure 1. Respiratory burst activity as mean fluorescence intensity of rabbit granulocytes after infusion of $0.2 \mu \mathrm{g} \cdot \mathrm{kg}^{-1} \cdot \mathrm{min}^{-1}$ endothelin-1 (solid bars) and control group (open bars). ${ }^{*} p<.05$ ET-1 vs. control group.

Phagocytosis Activity of Neutrophil. Phagocytosis activity, expressed as mean fluorescence intensity per cell, before ET-1 infusion did not differ significantly between the two groups (control group, $56 \pm 13$ vs. ET-1 group, $76 \pm 23$ ). It remained widely unchanged until the end of the observation period (control group, $46 \pm 12$ vs. ET-1 group, $66 \pm 24$ ) without significant differences between the groups.

Microbiological Results. In all groups, the blood cultures were found to be sterile before the injection of bacteria. In the control group, the number of bacteria decreased rapidly within 30 mins after bacterial injection. After 120 mins, bacteria were no longer detectable in the blood. The elimination of bacteria was markedly prolonged in the ET-1 group in which circulating bacteria were detectable until the end of the experiment (Fig. 2). Colonyforming units in the blood were higher $(p$ $<.01$ ) in the ET-1 group from 60 mins after the application of E. coli until the end of the experiments $(27 \pm 14 \mathrm{CFU}$ vs. sterile blood culture in the control group). After injection of $E$. coli, the delayed bacterial clearance from the circulation during ET-1 infusion was accompanied by a higher colonization in organs (Fig. 3). Tissue cultures from the control group showed the highest bacterial numbers in the liver $\left(4.0 \pm 0.9 \times 10^{4} \mathrm{CFU}\right)$ and the spleen $\left(2.3 \pm 0.5 \times 10^{4} \mathrm{CFU}\right)$. Lower counts were detected in the lung (750 $\pm 120 \mathrm{CFU})$ and the kidney $(360 \pm 150$ CFU). In contrast to this, ET-1 infusion resulted in an altered organ distribution pattern with highest amounts of $E$. coli in the spleen $\left(1.4 \pm 0.5 \times 10^{5} \mathrm{CFU}\right)$, followed by the liver $\left(7.4 \pm 2.8 \times 10^{4}\right.$ $\mathrm{CFU})$, the lung $\left(3.6 \pm 0.5 \times 10^{3} \mathrm{CFU}\right)$, and the kidney $(760 \pm 320 \mathrm{CFU})$. Significant statistical differences in bacterial counts were found in the spleen $(p<.05)$ and the lung $(p<.01)$ compared with the control group.

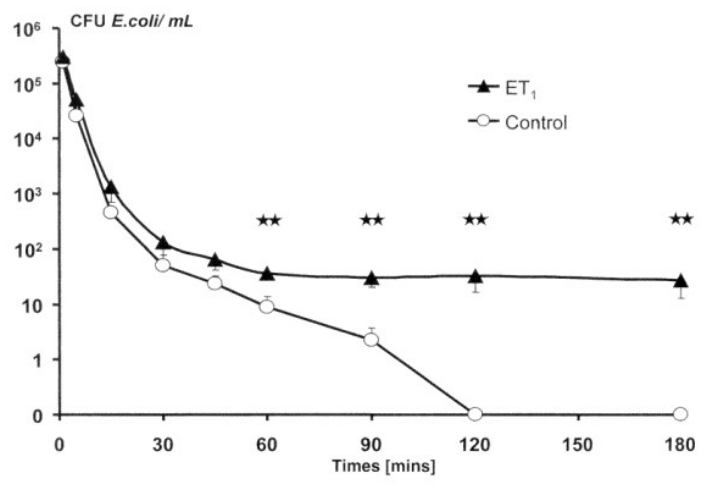


Figure 2. Elimination of Escherichia coli from blood of control group (circles) and after infusion of $0.2 \mathrm{\mu} \mathrm{g} \cdot \mathrm{kg}^{-1} \cdot \mathrm{min}^{-1}$ endothelin-1 (triangles). Mean counts of colony-forming units $(C F U) / \mathrm{mL}$ are plotted semilogarithmically against time in minutes. $* * p<.01$ ET-1 group vs. control group.
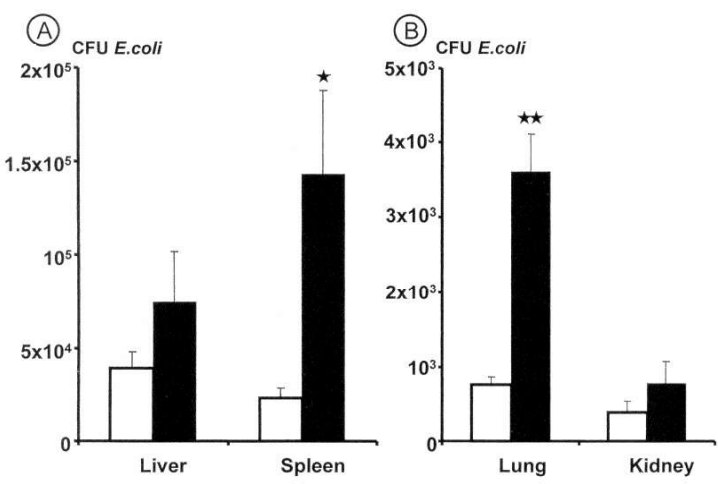

Figure 3. Bacterial counts per gram in different organs at $3 \mathrm{hrs}$ after injection of $10^{8}$ colony-forming units $(C F U)$ of Escherichia coli in control group (open bars) and during infusion of $0.2 \mu \mathrm{g} \cdot \mathrm{kg}^{-1} \cdot \mathrm{min}^{-1}$ endothelin-1 (solid bars). Liver and spleen, left; lung and kidney, right. $* p<.05$. $* * p$ $<.01$ ET-1 group vs. control group.

Lipopolysaccharide Clearance. To determine the concentration of endotoxin injected with the $E$. coli suspension and to study the clearance rate during the infusion of ET-1, LPS levels were measured before the injection of E. coli, and at 30,60, 120, and 180 mins. No endotoxin was detectable before injection of bacteria in any group. In the control and the ET-1 groups, endotoxin levels continuously decreased after bacterial injection until the end of the experiment, in the control group from $200 \pm 23$ to $40 \pm$ $15 \mathrm{ng} / \mathrm{mL}$ and in the ET-1 group from 211 \pm 21 to $25 \pm 14 \mathrm{ng} / \mathrm{mL}$.

\section{Nitrite and Nitrate}

Nitrite and nitrate levels as an indicator for ET-1-induced, NO-synthesis activity were measured before and during ET-1 infusion. Baseline values of $\mathrm{NO}_{\mathrm{x}}$ were similar in both groups (control group $18 \pm$
$3 \mu \mathrm{mol} / \mathrm{L}$; ET-1 $18 \pm 3 \mu \mathrm{mol} / \mathrm{L})$. Until the end of the observation period, no major changes were detectable within or between the groups (control group $20 \pm 3 \mu \mathrm{mol} / \mathrm{L}$; ET-1 $17 \pm 3 \mu \mathrm{mol} / \mathrm{L})$.

Hemodynamic and Metabolic Variables. In the control group, mean arterial blood pressure, hemoglobin, hematocrit, and blood gases $\left(\mathrm{PaO}_{2}, \mathrm{PaCO}_{2}\right.$, $\mathrm{SaO}_{2}, \mathrm{pH}$ ) remained within $10 \%$ of 0 values during the observation period. Baseline values of mean arterial pressure (MAP) were comparable in both groups $(55 \pm 3$ vs. 55 $\pm 4 \mathrm{~mm} \mathrm{Hg}$ in the control and ET-1 groups, respectively). A sustained increase in MAP was registered after the onset of the ET-1 infusion (Fig. 4) and compared with the control group, significant elevations were reached from -15 to 15 mins $(p<.05)$ until the end of the observation period $(p<.01)$. $E$. coli injection $(0 \mathrm{~min})$ induced a transient pressure increase of $\sim 10 \mathrm{~mm} \mathrm{Hg}$ in both groups. Mean arterial pressure decreased progressively in the control group to $40 \pm 2$ $\mathrm{mm} \mathrm{Hg}$ at the end of the observation period. In the ET-1 group, MAP reached maximum values immediately after the injection of $E$. coli $(79 \pm 5 \mathrm{~mm} \mathrm{Hg})$. Until the end of the experiment, a decrease in arterial pressure to final values of $50 \pm 3 \mathrm{~mm} \mathrm{Hg}$ was observed but MAP remained significantly higher in the ET-1 group than in the control group.

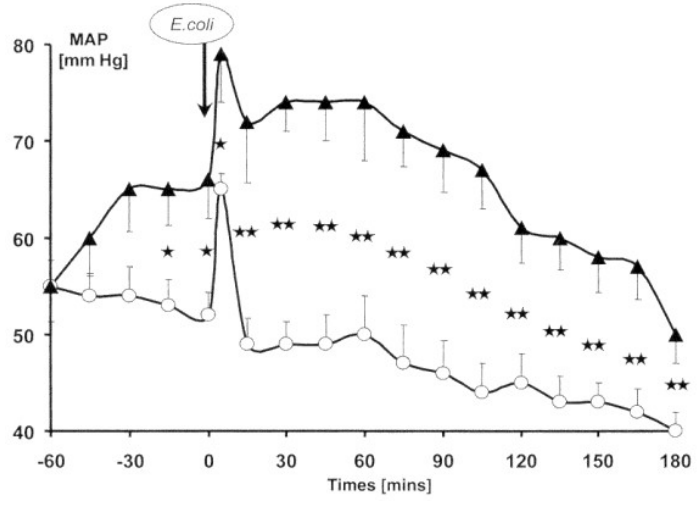

Figure 4. Mean arterial blood pressure $(M A P)$ in rabbits treated with $0.2 \mu \mathrm{g}^{\bullet} \mathrm{kg}^{-1} \bullet$ 
$\min ^{-1}$ endothelin-1 (triangles) and in sodium chloride-treated control group (circles). At time point $0 \mathrm{~min} 10^{8}$ colony-forming units $E$. coli were injected $(* p<.05 ; * * p<.01)$.

There was a continuous increase in serum lactate concentrations in both groups more pronounced in the ET-1 group with a four-fold increase from 60 mins $(0.4 \pm 0.1$ $\mathrm{mmol} / \mathrm{L})$ until the end of the experiments $(1.4 \pm 0.1 \mathrm{mmol} / \mathrm{L} ; p<.01$ vs. the control group). Minimal changes in hemoglobin and hematocrit, comparable in all groups, ensued from dilution effects caused by blood sampling and isovolemic substitution with saline.

White Blood Cell Counts. A decrease in granulocyte counts in the circulating blood has also been observed in both groups. Granulocyte counts were comparable in both groups at the beginning of the experiments $\left(3.6 \pm 0.7 \times 10^{3}\right.$ cells $/ \mu \mathrm{L}$ in the control group and $3.7 \pm 0.5 \times 10^{3}$ cells $/ \mu \mathrm{L}$ in the ET-1 group). At 150 mins thereafter, significant lower counts of granulocytes were found in the ET-1 group as compared with untreated control group $(0.9 \pm 0.3 \times$ $10^{3}$ cells $/ \mu \mathrm{L}$ in the control group vs. $0.3 \pm$ $0.1 \times 10^{3}$ cells $/ \mu \mathrm{L}$ in the ET- 1 group; $p$ $<.05)$.

Histology. In contrast to the control group, signs of hypoperfusion in liver, such as hydropic swelling of cells and the loss of nuclei, were observed by light microscopy of organ slices in the ET-1 group. Furthermore, a perisinusoidal infiltration was observed. Regarding the morphology of the other organs, no major differences were found between the ET-1 and the control group.

\section{DISCUSSION}

The activation of immunocompetent cells, particularly in mononuclear phagocytes and neutrophils, plays a key role in the sequel of inflammatory reactions. Under physiologic conditions, these reactions serve to eliminate invading microorganisms via phagocytosis and killing by toxic oxygen radicals and proteases. Nosocomial infections are the most common complications in intensive care units, leading to acute respiratory distress syndrome or multiple organ failure (21). In view of therapeutic strategies, many studies have been performed to describe the relationship between critical illness and the enhanced predisposition of the organism for microbial invasion. A link between shock and development of bacteremia and endotoxemia has often been reported (22, 23). In animal models, a shock-induced immune suppression has been demonstrated $(2,24)$. Also, induction of a hemorrhagic shock resulted in an impaired inflammatory response (25) and a reduced peritoneal bacterial clearance (26). Because the gut has been identified as a source of bacteremia, intestinal hypoperfusion was found to be related to the loss of intestinal barrier function and bacterial translocation into other organs (27). Increased ET-1 levels have often been reported after endotoxin exposure (10) or in sepsis (8). Although vascular reactions caused by the release of ET-1 are well documented (28), less is known about the effects of ET-1 on host defense mechanisms. Therefore, we designed this study to evaluate the potential influence of ET-1 on neutrophil functions and bacterial clearance and to determine the role of ET-1 in mediating septic complications. This study did not investigate altered translocation from the gut, but rather, whether host defense mechanisms are impaired after infusion of ET-1. The injection of $E$. coli was chosen as a correlate of bacterial invasion from various compartments, e.g., the gut, the urogenital tract, wounds, or catheters into the circulation. 
Compared with the control group, treatment with ET-1 reduced neutrophil respiratory burst activity and delayed bacterial elimination from the blood. Differences in PMN burst activity between the control group and the ET-1 group occur after onset of ET-1 infusion reaching significance 5 mins after $E$. coli injection (Fig. 1). Conflicting results have been obtained concerning the ability of ET-1 to activate leukocytes. Although some investigators described the neutrophilactivating properties of ET-1 (6), others reported unchanged activation levels (29) or even inhibition of leukocyte endothelium interactions (30). The elimination of bacteria from the blood is a multifactorial process. After chemotaxis, adherence, and phagocytosis, bacterial killing is finally achieved by respiratory burst. Thus, disturbance of one of the mechanisms is capable of interrupting the bactericidal capacity of the blood. The observed suppression of oxidative burst might be a correlate of the impaired bacterial clearance in blood and tissues. The reduced burst activity, however, was paralleled by an unaffected PMN phagocytosis activity. One can only speculate whether the reduced burst activity limits the killing of phagotized bacteria. This hypothesis is supported by our data of reduced burst activity during ET-1 infusion associated with an impaired bacterial elimination from blood and organs. During further observation, after a delayed elimination of $E$. coli, the number of injected E. coli (Fig. 2) decreased rapidly in the blood within the first 15 mins in both groups. Furthermore, significantly higher tissue colonization was found in lung and spleen tissue in the ET-1 group.

Few data exist concerning depressive effects of ET-1 on immune functions. Some investigators $(31,32)$ described a significant neutropenia after ET-1 infusion. Other groups (6) found that ET-1 induces PMN migration into vessel wall and subsequent elastase release, thereby causing tissue injury. Moreover, monocytic release of tumor necrosis factor a has been demonstrated after ET-1 $(33,34)$. Tumor necrosis factor a is known to impair bacterial clearance leading to enhanced organ colonization (24). The described actions of ET-1 may contribute to a reduced bacterial killing and to an increased vascular permeability.

Because ET-1 has been reported to release nitric oxide (NO) from the endothelium (35), $\mathrm{NO}_{\mathrm{x}}$ levels have been measured in the current study. No changes, however, were observed. Thus changes in MAP are not attributable to a modulation of extracellular measurable NO. Nevertheless, intracellular levels of NO, which also could affect vascular tone, were not investigated in the current study. Considerations in how far the observed ET-1-induced vasoconstriction (Fig. 4) contributes to the observed immunologic effects, remain speculative. Enhanced vascular resistance after ET-1 application has been found in the systemic circulation (36), as well as in kidneys (37), lungs (38), and intestines (39). In a previously published study (40), we investigated the effects of norepinephrine in our model and observed delayed bacterial elimination from the circulation. Thus, hypoperfusion and subsequent tissue hypoxia, reflected by the observed increase in lactate concentrations and the hydropic cell swelling in the liver, might contribute to decreased cellular bacterial killing. Altered immune functions resulting from ET-1 on cellular levels have been described $(6,29$ 32 ), but conclusions concerning the effects on host defense have not been drawn. Endothelin-1-induced effects on immune functions, however, seem to be multifactorial. On the one hand, the attenuation of neutrophil respiratory burst, and on the other hand, hemodynamic effects 
resulting from vasoconstriction, followed by hypoperfusion and subsequent tissue hypoxia, may be responsible for the observed impairment of bacterial killing.

In summary of our results, ET-1 impairs respiratory burst and bacterial clearance from the blood and tissue. Thus, elevated levels of ET-1 during sepsis could contribute to disturbances in immune functions, increasing the risk of bacterial infections. Our results indicate the crucial role of ET-1, not only as a regulator of vascular tone, but also as an important mediator affecting immune functions.

\section{ACKNOWLEDGMENT}

We thank Birgit Kaschta and Sylvia Thuy of the Institute of Medical Microbiology and Hygiene, University Hospital, Mannheim, Germany; Kerstin Salomon, Jutta Schulte, Angelika Tapper, and Monika Lehmer of the Institute of Anesthesiology, University Hospital of Mannheim, Germany; and Jutta Christophel of the Center of Medical Research, University Hospital, Mannheim, Germany, for excellent technical assistance.

\section{REFERENCES}

1. Koch T, Annuss C, Schiefer HG, et al: Impaired bacterial clearance after activation of the complement and coagulation systems. Shock 1997; 7:42-48

2. Koch T, Duncker HP, Axt R, et al: Effects of hemorrhage, hypoxia, and intravascular coagulation on bacterial clearance and translocation. Crit Care Med 1993; 21:1758-1764

3. Yanagisawa M, Kurihara H, Kimura S, et al: A novel potent vasoconstrictor peptide produced by vascular endothelial cells. Nature 1988; 332:411-415
4. Schmeck J, Janzen R, Münter K, et al: Endothelin-1 and thromboxane A2 increase pulmonary vascular resistance in granulocyte-mediated lung injury. Crit Care Med 1998; 26:1868-1874

5. Chalmers GW, Little SA, Patel KR, et al: $\quad$ Endothelin-1-induced bronchoconstriction in asthma. Am J Resp Crit Care Med 1997; 156:382388

6. Halim A, Kanayama N, El Maradny E, et al: Activated neutrophil by endothelin-1 caused tissue damage in human umbilical cord. Thromb Res 1995; 77:321-327

7. Eguchi K, Kawakami A, Nakashima $\mathrm{M}$, et al: Stimulation of mitogenesis in human thyroid epithelial cells by endothelin. Acta Endocrin 1993; 128:215-220

8. Voermann HJ, Stehouwer CD, van Kamp GJ, et al: Plasma endothelin levels are increased during septic shock. Crit Care Med 1992; 20:10971101

9. Weitzberg E, Lundberg JM, Rudehill A: Elevated plasma levels of endothelin in patients with sepsis syndrome. Circ Shock 1991; 33:222227

10. Kaddoura S, Curzen NP, Evans TW, et al: Tissue expression of endothelin-1 mRNA in endotoxemia. Biochem Biophys Res Commun 1996; 218:641647

11. Kaw S, Hecker M, Southan GJ, et al: Characterization of serine proteasederived metabolites of big endothelin in the cytosolic fraction from human polymorphonuclear leukocytes. $J$ Cardiovasc Pharm 1992; 20(Suppl 12):S22-S24

12. Heller A, Ragaller M, Schmeck J, et al: Role of NO and endothelin in hemoglobin-induced pulmonary 
vasoconstriction. Shock 1998; 10:401406

13. Dschietzig T, Laule M, Alexiou $\mathrm{K}$, et al: Coronary constriction and consequent cardiodepression in pulmonary embolism are mediated by pulmonary big endothelin and enhanced in early endothelial dysfunction. Crit Care Med 1998; 26:510-517

14. Cunningham ME, Huribal M, Bala RJ, et al: Endothelin-1 and endothelin-4 stimulate monocyte production of cytokines. Crit Care Med 1997; 25:958-964

15. Emmendörfer A, Hecht M, LohmannMatthes M-L, et al: A fast and easy method to determine the production of reactive intermediates by human and murine phagocytes using dihydrorhodamine 123. J Immunol Methods 1990; 131:269-275

16. Rothe G, Kellermann W, Valet G: Flow cytometric parameters of neutrophil function as early indicators of sepsis or trauma related pulmonary or cardiovascular organ failure. $J L a b$ Clin Med 1990; 115:52-61

17. Sandys GH: A new method of preventing swarming of Proteus $s p$. with a description of a new medium suitable for use in routine laboratory practice. J Med Lab Technol 1960; 17:224-233

18. Urbaschek B, Becker K-P, Ditter B, et al: Quantification of endotoxin and sample-related interferences in human plasma and cerebrospinal fluid by using a kinetic limulus amebocyte lysate microtiter test. In: Microbiology. Leive L (ed). Washington, DC, American Society for Microbiology, 1985, pp 39-43

19. Ditter B, Becker K-P, Urbaschek R, et al: Quantitativer endotoxinnachweis, automatisierter, kinetischer limulusamöbozytenlysat-mikrotiter-test mit messung probenabhängiger interferenzen. Drug Res 1983; 33:681687

20. Green LC, Wagner DA, Glogowski J: Analysis of nitrate, nitrite and [15N] nitrate in biological fluids. Ann Biochem 1982; 126:131-138

21. Bone RC, Balk RA, Cerra FB, et al: Definitions for sepsis and organ failure and guidelines for the use of innovative therapies in sepsis. Chest 1992; 101:1644-1655

22. Zweifach BW, Benacerraf B, Thomas L: The relationship between the vascular manifestations of shock produced by endotoxin, trauma, and hemorrhage. II. The possible role of the reticuloendothelial system in resistance to each type of shock. $J$ Exp Med 1957; 106:403-414

23. Fine J, Ruthenberg S, Schweinburg FB: The role of the reticuloendothelial system in hemorrhagic shock. $J$ Exp Med 1959; 110:547-569

24. Koch T, Duncker HP, Axt R, et al: Alterations of bacterial clearance induced by endotoxin and tumor necrosis factor. Infect Immun 1993; 61:3143-3148

25. Abraham E, Chang YH: Effects of hemorrhage on inflammatory response. Arch Surg 1987; 119:1154-1157

26. Fink MP, Gardiner M, MacVittie TJ: Sublethal hemorrhage impairs acute peritoneal response in rats. $J$ Traumatol 1985; 25:234-237

27. Baker JW, Deitch EA, Berg RD, et al: Hemorrhagic shock induces bacterial translocation from the gut. $J$ Traumatol 1988; 28:94-101

28. Masaki T, Yanagisawa M: Cardiovascular effects of the 
endothelins. Cardiovasc Drug Rev 1990; 8:373-385

29. Kopprasch S, Gatzweiler A, Kohl M, et al: Endothelin-1 does not prime polymorphonuclear leukocytes for enhanced production of reactive oxygen metabolites. Inflammation 1995; 19:679-687

30. Murohara T, Lefer AM: Autocrine effects of endothelin-1 on leukocyteendothelial interaction: Stimulation of endothelin B receptor subtype reduces endothelial adhesiveness via a nitric oxide-dependent mechanism. Blood 1996; 88:3894-3900

31. Lopez Farre A, Riesco A, Espinosa G, et al: Effect of endothelin-1 on neutrophil adhesion to endothelial cells and perfused heart. Circulation 1993; 88:1161-1171

32. Filep JG, Fournier A, Foldes-Filep E: Acute pro-inflammatory actions of endothelin-1 in the guinea-pig lung: Involvement of ETA and ETB receptors. $\mathrm{Br} J$ Pharmacol 1995; 115:227-236

33. McMillen MA, Huribal M, Kumar R, et al: Endothelin-stimulated human monocytes produce prostaglandin $\mathrm{E}_{2}$ but not leukotriene $\mathrm{B}_{4}$. J Surg Res 1993; 54:331-335

34. McMillen MA, Sumpio BE: Endothelins: Polyfunctional cytokines. $J$ Am Coll Surg 1995; 180:621-637

35. Michael JR, Markewitz BA: Endothelins and the lung. Am J Respir Crit Care Med 1996; 154:555-581

36. Miyauchi T, Tomobe Y, Shiba R, et al: Involvement of endothelin in the regulation of human vascular tonus. Potent vasoconstrictor effect and existence in endothelial cells. Circulation 1990; 81:1874-1880

37. Pernow J, Boutier JF, Franco-Cereceda A, et al: Potent selective vasoconstrictor effects of endothelin in the pig kidney in vivo. Acta Physiol Scand 1988; 134:573-574

38. Barnard JW, Barman SA, Adkins WK, et al: Sustained effects of endothelin-1 on rabbit, dog, and rat pulmonary circulations. Am J Physiol 1991; 261:H479-H486

39. Ahlborg G, Weitzberg E, Lundberg JM: Circulating endothelin-1 reduces splanchnic and renal blood flow and splanchnic glucose production in humans. J Appl Physiol 1995; 79:141145

40. Koch T, Heller S, van Ackern K, et al: Impairment of bacterial clearance induced by norepinephrine infusion in rabbits. Int Care Med 1996; 22:637643

\section{Society of Critical Care Medicine VISION STATEMENT}

SCCM envisions a health system in which all critically ill and injured persons will obtain care that promotes desired outcomes for individuals and society, is consistent with emerging knowledge, and occurs in a humane and respectful manner.

Adopted by the SCCM Council September 28, 1997 